\title{
Monoclonal antibodies for the treatment of chronic rhinosinusitis with nasal polyposis: a systematic review*
}

\author{
Nikolaos Tsetsos' ${ }^{1}$ John K. Goudakos', Dimitrios Daskalakis², \\ Iordanis Konstantinidis ${ }^{3}$, Konstantinos Markou ${ }^{3}$ \\ 'Department of Otorhinolaryngology-Head and Neck Surgery, 424 General Military Hospital, Thessaloniki, Greece \\ 2 Department of Otorhinolaryngology-Head and Neck Surgery, Diana Princess of Wales Hospital, Grimsby, United Kingdom \\ ${ }^{3}$ 2nd Academic Otorhinolaryngology-Head and Neck Surgery Department, Aristotle University of Thessaloniki, Papageorgiou \\ Hospital, Thessaloniki, Greece
}

Rhinology 56: 11-21, 2018

https://doi.org/10.4193/Rhino17.156

*Received for publication:

July 17,2017

Accepted: December 21, 2017

\begin{abstract}
Background: Monoclonal antibodies have been proposed as a novel therapy in patients suffering from chronic rhinosinusitis with nasal polyposis (CRSwNP). The purpose of this systematic review was to evaluate their efficacy and safety.

Methodology: A literature search was performed in MEDLINE, Web of Science, the Cochrane Library and multiple trial registries followed by extensive hand-searching for the identification of relevant studies. Only randomized controlled trials (RCTs) comparing the use of monoclonal antibodies with placebo or another therapy in adult patients with CRSwNP were included.

Results: Anti-immunoglobin E (IgE) therapy with omalizumab was assessed in two studies, anti-interleukin (IL)-5 therapy in three studies (1 reslizumab, 2 mepolizumab) and finally anti-IL-4 and anti-IL-13 therapy in only one. With the exception of one study, biologic therapy was proved to be effective in reducing total nasal endoscopic polyp score (TPS) in treatment as compared to placebo groups. Monoclonal antibodies brought about improvement in several other outcomes, such as opacification in computed tomography (CT), quality of life measures, nasal airflow, olfaction and type 2 helper T-cell (Th2) associated biomarkers. Overall, the use of these agents was deemed safe and well-tolerated.
\end{abstract}

Conclusions: This is the first systematic review showing encouraging results for the use of all three main categories of monoclonal antibodies in CRSwNP patients and highlights the need for further well-designed and with larger sample sizes RCTs.

Key words: chronic rhinosinusitis, nasal polyps, asthma, biologic therapy, monoclonal antibodies

\section{Introduction}

Chronic rhinosinusitis (CRS) is a complex disease, affecting approximately $11,9 \%$ and $10,9 \%$ of the general population in the United States and Europe respectively ${ }^{(1,2)}$. According to the European Position Paper on Rhinosinusitis and Nasal Polyps (EPOS), CRS is characterized by the presence of both subjective and objective evidence of chronic sinonasal inflammation for more than 12 weeks ${ }^{(3)}$ and includes several distinguished clinical entities, the most important of which are CRS with nasal polyposis (CRSwNP) and CRS without nasal polyposis (CRSsNP)

(4). CRSwNP is a debilitating disease that has a substantial impact on the patient's quality of life with its overall annual economic burden in the United States to be estimated around $\$ 22$ billion in 2014 (direct and indirect costs) ${ }^{(5)}$. Despite the fact that its etiology remains elusive, CRSwNP is often associated with allergy, asthma, infection, fungi, cystic fibrosis, and aspirin sensitivity ${ }^{(3)}$. The connection between CRSwNP and bronchial asthma has been extensively investigated by numerous studies, with the co-incidence of CRSwNP and asthma to be about $20-70 \%{ }^{(6-8)}$. The comparison between patients suffering from both CRSWNP and asthma and those without asthma has proved that high levels of eosinophil cationic protein (ECP), IgE and Staphylococcus aureus enterotoxin $\lg \mathrm{E}(\mathrm{SE}-\mathrm{lg} \mathrm{E})$ in the nasal polyps are substantially associated with asthma comorbidity ${ }^{(8)}$. Furthermore, increased levels of $\lg \mathrm{E}, \mathrm{SE}-\mathrm{IgE}$, IL-5 and ECP are also linked with a more serious form of CRSwNP with more frequent recurrence after 
surgery ${ }^{(9)}$.

The strong connection of nasal polyposis and asthma combined with the encouraging results of biologic therapy in patients suffering from asthma motivated researchers to conduct studies evaluating the potential use of different monoclonal antibodies in a subgroup of patients mainly suffering from nasal polyposis and comorbid asthma. Three main biological therapies have been assessed regarding their efficacy and safety in adult patients with CRSwNP: Omalizumab is an anti-IgE monoclonal antibody approved in the European Union and the United States for the treatment of severe allergic asthma ${ }^{(10)}$. Considering the high total IgE levels in nasal secretions, polyp tissue, and serum of patients with CRSwNP combined with their relevance in patients with allergic asthma, omalizumab has been assessed as a potential treatment in the subgroup of patients with CRSwNP and comorbid asthma. Furthermore, prominent eosinophilia is characteristic in more than $80 \%$ of Caucasian patients with CRSwNP(11). IL-5 is a key mediator in chemotaxis, differentiation, activation, and survival of eosinophils and is detected in high levels in patients with CRSWNP ${ }^{(12,13)}$. Hence, preventing free circulating IL-5 from binding to the IL-5R subunit a (IL-5Ra) expressed on the surface of eosinophils has been proposed as a new treatment strategy in these patients. For this purpose, two different monoclonal antibodies have been evaluated, reslizumab and mepolizumab ${ }^{(14)}$. Lastly, dupilumab is a human monoclonal antibody (mAb) that binds to the IL-4 receptor alpha subunit (IL-4Ra) inhibiting signaling of both IL-4 and IL-13 $3^{(15)}$, two type 2 helper T-cell (Th2) associated cytokines that play a major role in the pathogenesis of nasal polyposis. This type of biologic therapy has previously shown clinical benefit in patients with asthma and atopic dermatitis and could not have been omitted in the research of nasal polyposis ${ }^{(16,17)}$.

The aim of this study is to review all existing evidence concerning the efficacy and safety of monoclonal antibodies used for the treatment of adults with chronic rhinosinusitis with nasal polyposis.

\section{Methods}

\section{Search strategy}

Two reviewers (NT and DD) independently performed a comprehensive literature search in MEDLINE, Web of Science and the Cochrane Library electronic databases from September 20th to November 20th, 2016 to identify studies that answered the question of interest. For this purpose, the following free-text terms were used: rhinosinusitis or sinusitis or rhinitis or nasal polyp* combined with monoclonal antibodies or humanized or anti-IgE or anti-IL5 or omalizumab or mepolizumab or dupilumab or reslizumab and therapy or treatment or management and limited to humans. Additionally, they searched for eligible trials in multiple trial registries, including clinicaltrial.gov, the European Union (EU) Clinical Trials Register and the Internatio- nal Clinical Trials Registry Platform. The ProQuest Dissertations $\&$ Theses (PQDT) database was searched as a source of grey literature. Extensive hand searching of the references of all retrieved studies and relevant review articles was also performed. Finally, researchers contacted pharmaceutical companies and experts via e-mail in order to obtain unpublished work. No time or language limitation was applied. As this study was a systemic review of published articles, neither informed consent nor ethics approval was required.

\section{Selection of studies}

The study selection process was carried out independently by the two reviewers and disagreements were resolved by consensus. The inclusion and exclusion criteria of studies in this systematic review were specified prior to the literature search. Any studies that met the following criteria were eligible for inclusion: 1) randomized controlled trials (RCTs) comparing the use of monoclonal antibodies therapy with placebo or another therapy 2 ) the study population comprised adult patients ( $>18$ years old) with CRS with nasal polyposis, 3) outcomes measured were change in computed tomography (CT) score, change in clinical polyp score, change in quality of life, change in cellular inflammation, change in nasal airflow, change in olfaction and change in Th2 associated biomarkers.

Studies were excluded if: 1) they included patients with CRS without nasal polyposis 2) included patients suffering from medical conditions with established association with nasal polyposis, such as cystic fibrosis, Churg-Strauss syndrome, Kartagener's syndrome, and ciliary dyskinesia, 3) they included patients with allergic fungal rhinosinusitis.

\section{Data extraction and quality assessment}

Two reviewers (NT and DD) independently reviewed each study according to the predefined criteria for eligibility, and, finally, extracted data. Any disagreement in the process of study selection or data extraction was resolved through consensus. A predefined form was used to extract data from each study. The following data was recorded from each of the eligible studies: general characteristics (first author, year of publication, country, study design, study sample, age, sex, diagnosis, length of followup, type of intervention, intervention protocol), outcome data (primary and secondary outcomes) and finally minor and major reported side-effects.

The Cochrane Risk of Bias Tool was used to assess the quality of the included studies. Two independent reviewers performed the quality assessment and any uncertainties were resolved through consensus. A score of "high," "low," or "unclear" was assigned to the following items: 1) random sequence generation, 2) allocation concealment, 3) blinding of participants and personnel, 4) blinding of outcome assessment, (5) incomplete outcome data, 6) selective outcome reporting, and 7) other sources of bias. 
Table 1. Total polyp score (TPS).

\begin{tabular}{|cl|}
$\begin{array}{c}\text { Polyp } \\
\text { score }\end{array}$ & Polyp size \\
\hline 0 & No polyps \\
\hline 1 & $\begin{array}{l}\text { Small polyps in the middle meatus not reaching below the } \\
\text { inferior border of the middle concha }\end{array}$ \\
\hline 2 & $\begin{array}{l}\text { Polyps reaching below the lower border of the middle } \\
\text { turbinate }\end{array}$ \\
\hline 3 & $\begin{array}{l}\text { Large polyps reaching the lower border of the inferior turbi- } \\
\text { nate or polyps medial to the middle concha }\end{array}$ \\
\hline 4 & $\begin{array}{l}\text { Large polyps causing complete obstruction of the inferior } \\
\text { meatus }\end{array}$ \\
\end{tabular}

\section{Outcomes}

The primary outcome of interest in this study was the reduction in total nasal endoscopic polyp score (TPS). Polyps were evaluated on each side by means of nasal endoscopy at each visit and graded based on polyp size resulting in scores of 0 to 4 ; higher score indicated worse status. TPS was defined as the sum of the left and the right nostril (Table 1).

Secondary end points included change in Lund-Mackay (CT) score, percentage in sinus opacification as determined by $\mathrm{CT}$ imaging, Sino-nasal Outcome Test (SNOT-20 and SNOT-22 score), 36-Item Short Form Survey (SF-36 score) University of Pennsylvania Smell Identification Test (UPSIT score), Peak Nasal Inspiratory Flow (PNIF), eosinophil count, serum and nasal IL-5Ra, serum and nasal ECP. Safety was assessed on the basis of major and minor adverse events reported in the studies. Researchers decided to include outcome measures reported in at least two different studies. If available, statistical data, such as confidence intervals, standard deviations, p-values etc. were mentioned; if not, results were only narratively described.

\section{Statistical analysis}

The ultimate objective of this research was to culminate in a quantitative synthesis of the main outcome measures. However, the small number of the included studies, the small sample sizes, the lack of reported data (the effort to communicate with most authors was fruitless) coupled with different outcome measures and follow-ups made it impossible to lead to a metaanalysis.

\section{Results}

Literature search

The systematic search in bibliographic databases yielded a number of 1089 studies. Three additional records from trial registries were also identified, two of which were not eligible for the study. After removing duplicates, 803 publications were available for title-abstract screening. Finally, eight articles that could provide data able to answer the research question were

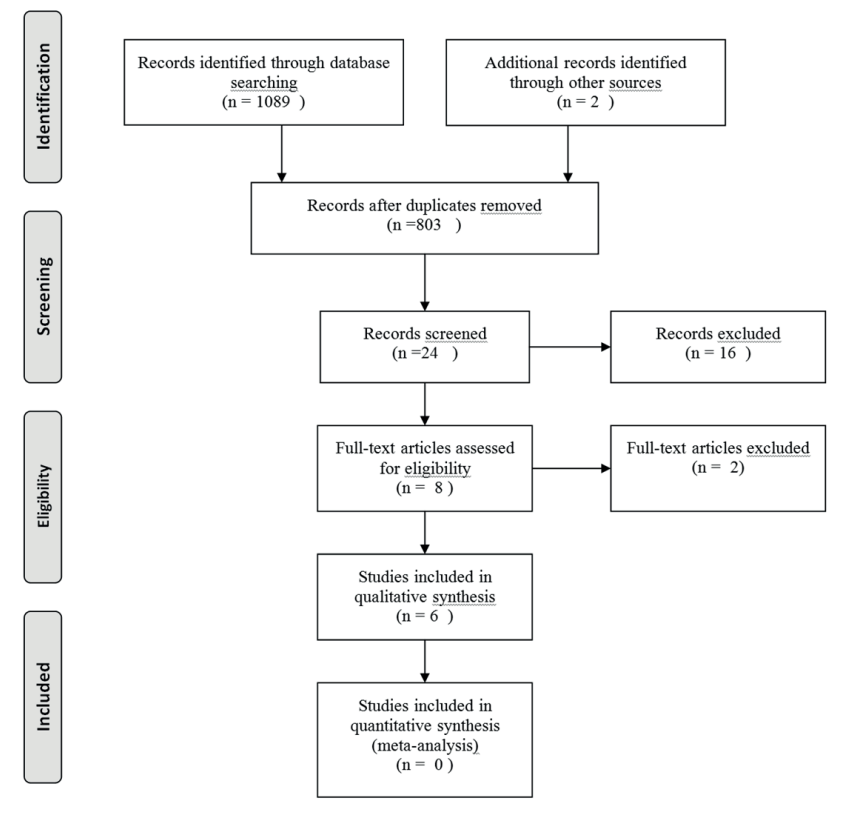

Figure 1. Literature search strategy. PRISMA flowchart detailing literature search and review.

identified. The full-text of these studies was examined thoroughly resulting in six RCTs that investigated the efficacy of monoclonal antibodies on the management of patients with CRSWNP. The study flow diagram is depicted in Figure 1.

\section{Study characteristics}

Six studies fulfilled the inclusion criteria ${ }^{(18-23)}$. All studies were RCTs and were published between 2006 and 2017. A total of 256 patients were examined in the six RCTs, with 142 of them receiving monoclonal antibodies and 114 placebo. The total number of patients in these studies ranged from 14 to 105. Three of the studies were single-site ${ }^{(19-21)}$ while the other three were multisite ${ }^{(18,22,23)}$. Subjects were randomized to receive: anti-IL5 therapy with reslizumab ${ }^{(18)}$ or mepolizumab ${ }^{(20,23)}$ in three studies, anti-lgE therapy with omalizumab in two studies ${ }^{(19,21)}$ and anti-IL-4Ra therapy with dupilumab in the last $R C T^{(22)}$. The characteristics of the six included studies as well as baseline demographic and clinical characteristics of the patients are presented in Table 2 and 3. Risk of Bias Assessment is presented in Figures 2 and 3.

\section{Total Nasal Endoscopic Polyp score}

The reduction in TPS was assessed in all six studies (Table 4). In five of the six studies the use of monoclonal antibodies was proved effective in reducing nasal polyp burden in patients with CRSwNP. In particular, Gevaert et al. ${ }^{(18)}$ showed that the treatment with $1 \mathrm{mg} / \mathrm{kg}$ of reslizumab managed to improve the TPSs for up to 12 weeks in 5 of 8 patients. Furthermore, half of the subjects who received a single intravenous infusion of $3 \mathrm{mg} / \mathrm{kg}$ reslizumab presented a reduction in TPS for 4 weeks. A sub- 
Table 2. Characteristics of the RCTs included in the systematic review .

\begin{tabular}{|c|c|c|c|c|c|c|c|c|c|c|}
\hline Study & Country & Design & $\begin{array}{l}\text { To- } \\
\text { tal }\end{array}$ & lents ( & CRG & $\begin{array}{l}\text { Study } \\
\text { Popula- } \\
\text { tion }\end{array}$ & $\begin{array}{l}\text { Monoclonal } \\
\text { Antibody- } \\
\text { (Mechanism } \\
\text { of action) }\end{array}$ & Intervention Protocol & $\begin{array}{l}\text { Last } \\
\text { visit }\end{array}$ & $\begin{array}{l}\text { Primary } \\
\text { Outcome }\end{array}$ \\
\hline $\begin{array}{l}\text { Gevaert } \\
\text { et al. } \\
(2006)\end{array}$ & $\begin{array}{l}\text { Belgium, } \\
\text { Austria }\end{array}$ & $\begin{array}{l}\text { Randomised, } \\
\text { double-blind, } \\
\text { placebo control- } \\
\text { led study }\end{array}$ & 24 & 16 & 8 & CRSwNP & $\begin{array}{l}\text { Reslizumab } \\
\text { (anti-IL-5 } \\
\text { mAb) }\end{array}$ & $\begin{array}{l}3 \mathrm{mg} / \mathrm{kg} \text { or } 1 \mathrm{mg} / \mathrm{kg} \text { or placebo of } \\
\text { a single intravenous injection }\end{array}$ & $36 w$ & $\begin{array}{l}\text { Safety } \\
\text { and } \\
\text { pharma- } \\
\text { cokine- } \\
\text { tics }\end{array}$ \\
\hline $\begin{array}{l}\text { Pinto } \\
\text { et al. } \\
(2010)\end{array}$ & USA & $\begin{array}{l}\text { Randomised, } \\
\text { double-blind, } \\
\text { placebo control- } \\
\text { led study }\end{array}$ & 14 & 7 & 7 & $\begin{array}{l}\text { CRSwNP } \\
\text { or CRS- } \\
\text { sNP }\end{array}$ & $\begin{array}{l}\text { Omalizumab } \\
\text { (anti-lgE } \\
\mathrm{mAb})\end{array}$ & $\begin{array}{l}0,016 \mathrm{mg} / \mathrm{kg} \text { per IU total serum } \\
\mathrm{lgE} / \mathrm{ml} \text { subcutaneously at enrol- } \\
\text { lement and every } 4 \mathrm{w} \text { for } 24 \mathrm{w} \text { vs } \\
\text { placebo }\end{array}$ & $24 w$ & $\begin{array}{l}\text { Change } \\
\text { in sinus } \\
\text { CT opa- } \\
\text { cification }\end{array}$ \\
\hline $\begin{array}{l}\text { Gevaert } \\
\text { et al. } \\
(2011)\end{array}$ & Belgium & $\begin{array}{l}\text { Randomised, } \\
\text { double-blind, } \\
\text { placebo control- } \\
\text { led study }\end{array}$ & 30 & 20 & 10 & CRSwNP & $\begin{array}{l}\text { Mepolizumab } \\
\text { (anti-IL-5 } \\
\text { mAb) }\end{array}$ & $\begin{array}{l}2 \text { single intravenous inj of } 750 \\
\text { mg of mepolizumab or pla- } \\
\text { cebo( } 28 \text { days apart) }\end{array}$ & $48 w$ & $\begin{array}{l}\text { Change } \\
\text { in TPS }\end{array}$ \\
\hline $\begin{array}{l}\text { Gevaert } \\
\text { et al. } \\
(2013)\end{array}$ & Belgium & $\begin{array}{l}\text { Randomised, } \\
\text { double-blind, } \\
\text { placebo control- } \\
\text { led study }\end{array}$ & 24 & 16 & 8 & $\begin{array}{l}\text { CRSwNP } \\
\text { and co- } \\
\text { morbid } \\
\text { asthma }\end{array}$ & $\begin{array}{l}\text { Omalizumab } \\
\text { (anti-lgE } \\
\mathrm{mAb} \text { ) }\end{array}$ & $\begin{array}{l}\text { maximum dose of } 375 \mathrm{mg} \\
\text { subcutaneously(every } 2 \mathrm{w} / 8 \mathrm{inj} \text { in } \\
\text { total or every } \mathrm{m} / 4 \text { inj in total) of } \\
\text { omalizumab vs placebo }\end{array}$ & $20 w$ & $\begin{array}{l}\text { Change } \\
\text { in TPS }\end{array}$ \\
\hline $\begin{array}{l}\text { Bachert } \\
\text { et.al } \\
(2016)\end{array}$ & $\begin{array}{l}\text { USA, } \\
\text { Belgium, } \\
\text { Spain, } \\
\text { Sweden }\end{array}$ & $\begin{array}{l}\text { Randomised, } \\
\text { double-blind, } \\
\text { placebo control- } \\
\text { led study }\end{array}$ & 60 & 30 & 30 & CRSwNP & $\begin{array}{l}\text { Dupilumab } \\
\text { (anti-IL-4Ra } \\
\text { mAb) }\end{array}$ & $\begin{array}{l}\text { A } 600 \mathrm{mg} \text { loading dose of dupi- } \\
\text { lumab subcutaneously followed } \\
\text { by } 15 \text { weekly doses of } 300 \mathrm{mg} \\
\text { plus MFNS } 100 \mu \mathrm{g} \text { in each nostril } \\
\text { twice daily or matched placebo } \\
\text { for } 16 \mathrm{w}\end{array}$ & $16 w$ & $\begin{array}{l}\text { Change } \\
\text { in TPS }\end{array}$ \\
\hline $\begin{array}{l}\text { Bachert } \\
\text { et.al } \\
(2017)\end{array}$ & $\begin{array}{l}\text { Belgium, } \\
\text { Netherlands, } \\
\text { United King- } \\
\text { dom }\end{array}$ & $\begin{array}{l}\text { Randomised, } \\
\text { double-Blind, } \\
\text { placebo control- } \\
\text { led study }\end{array}$ & 105 & 54 & 51 & CRSwNP & $\begin{array}{l}\text { Mepolizumab } \\
\text { (anti-IL-5 } \\
\text { mAb) }\end{array}$ & $\begin{array}{l}\text { A total of six doses (one every } \\
4 \text { weeks) of mepolizumab } 750 \\
\text { mg by intravenous infusion or } \\
\text { matched placebo plus intranasal } \\
\text { steroids(two sprays of } 1 \mathrm{mg} / \mathrm{ml} \\
\text { fluticasone propionate daily) }\end{array}$ & $25 w$ & $\begin{array}{l}\text { Reduced } \\
\text { Need for } \\
\text { Surgery }\end{array}$ \\
\hline
\end{tabular}

TRG: treatment group, CRG: control group, CRSsNP: chronic rhinosinusitis without nasal polyposis, CRSwNP: chronic rhinosinusitis with nasal polyposis, MFNS: mometasone furoate nasal spray lgE: immunoglobulin E, IL: interleukin, IL-4Ra: interleukin-4 receptor alpha subunit, mAb: monoclonal antibody, TPS: total nasal endoscopic polyp score, no:number, w:weeks, m:months, inj: injections, pg: pictograms, ml:milliliters, mg:miligrams, kg:kilograms, IU: international unit

group analysis in the study showed that subjects who responded to reslizumab were found to have elevated nasal IL-5 levels at baseline, compared to the non-responders.

Gevaert et al. ${ }^{(20)}$ showed that mepolizumab improved significantly the TPSs in 12 of 20 subjects while no change was shown in the placebo group $(p=0,028)$. However, the subgroup analysis in this study showed that no difference for baseline TPSs and local IL-5 levels was found. Similarly, in the Bachert et al. ${ }^{(23)}$ study, mepolizumab caused a significant improvement in the treatment group as compared to control group from week 9 to week 25.

Concerning omalizumab, Pinto et al. ${ }^{(19)}$ did not manage to show any significant change in TPS in the treatment as compared to placebo group $(p<0,58)$. On the contrary, Gevaert et al. ${ }^{(21)}$ demonstrated that the treatment with omalizumab resulted in significant reduction in TPS compared to placebo $(p=0,01$ and $\mathrm{p}=0,99$, respectively).

Finally, in the study of Bachert et al. ${ }^{(22)}$ dupilumab showed a significant improvement in TPS in the treatment group as compared to mometasone sprays alone $(p<0,001)$. The difference was seen at week 4 and continued until the end of the treatment period (week 16). In addition, an improvement of at least 1 point in the polyp score was seen in $70 \%$ of the dupilumab plus mometasone group conversely to $20 \%$ of the subjects in the placebo plus mometasone group.

\section{CT score}

The change in CT score was evaluated in four of the six included studies (Table 4). Specifically, in three studies the outcome was the improvement in the percentage of sinus opacification in CT images ${ }^{(19,20)}$, in one study it was the Lund-Mackay CT score ${ }^{(21)}$ and in the last one both opacification in CT and the Lund-Mackay CT 
Table 3. Baseline demographic and clinical characteristics of the patients.

\begin{tabular}{|c|c|c|c|c|c|c|c|c|c|c|c|c|c|}
\hline & \multicolumn{3}{|c|}{$\begin{array}{l}\text { Gevaert et al. } \\
\qquad(2006)\end{array}$} & \multicolumn{2}{|c|}{$\begin{array}{l}\text { Pinto et al. } \\
\text { (2010) }\end{array}$} & \multicolumn{2}{|c|}{$\begin{array}{l}\text { Gevaert et al. } \\
\text { (2011) }\end{array}$} & \multicolumn{2}{|c|}{$\begin{array}{c}\text { Gevaert et al. } \\
\text { (2013) }\end{array}$} & \multicolumn{2}{|c|}{$\begin{array}{l}\text { Bachert et al. } \\
\quad(2016)\end{array}$} & \multicolumn{2}{|c|}{$\begin{array}{l}\text { Bachert et al. } \\
\text { (2017) }\end{array}$} \\
\hline & TRG1 & TRG2 & CRG & TRG & CRG & TRG & CRG & TRG & CRG & TRG & CRG & TRG & CRG \\
\hline \multirow[t]{2}{*}{ Age } & $\begin{array}{c}43,6 \\
(22-63)\end{array}$ & $\begin{array}{c}48,5 \\
(18-57)\end{array}$ & $\begin{array}{c}48 \\
(21-59)\end{array}$ & $\begin{array}{r}43,1 \\
\pm 9,8\end{array}$ & $\begin{array}{r}48,6 \\
\pm 9,1\end{array}$ & $\begin{array}{l}50,05 \\
(8,86)\end{array}$ & $\begin{array}{c}45,9 \\
(11,43)\end{array}$ & $\begin{array}{c}50 \\
(44-56)\end{array}$ & $\begin{array}{c}45 \\
(42-54)\end{array}$ & $\begin{array}{l}47,4 \\
(9,8)\end{array}$ & $\begin{array}{l}49,3 \\
(9,1)\end{array}$ & $\begin{array}{c}51 \\
(11)\end{array}$ & $\begin{array}{c}50 \\
(10)\end{array}$ \\
\hline & \multicolumn{3}{|c|}{ y (range) } & \multicolumn{2}{|c|}{ mean $\pm S D$} & \multicolumn{2}{|c|}{ mean (SD) } & \multicolumn{2}{|c|}{ median (IQR) } & \multicolumn{2}{|c|}{ mean (SD) } & \multicolumn{2}{|c|}{ mean (SD) } \\
\hline Sex (Female/male) & $2 / 6$ & $4 / 4$ & $2 / 6$ & $4 / 3$ & $0 / 7$ & $6 / 14$ & $2 / 8$ & $3 / 12$ & $4 / 4$ & $12 / 18$ & $14 / 16$ & $13 / 41$ & $17 / 34$ \\
\hline Asthma & $7 / 8$ & $5 / 8$ & $6 / 8$ & $7 / 7$ & $7 / 7$ & $10 / 20$ & $3 / 10$ & $15 / 15$ & $8 / 8$ & $16 / 30$ & $19 / 30$ & $44 / 54$ & $38 / 51$ \\
\hline Allergy & \multicolumn{3}{|c|}{ NR } & \multicolumn{2}{|c|}{ NR } & $10 / 20$ & $4 / 10$ & $7 / 15$ & $6 / 8$ & $18 / 26$ & $20 / 28$ & \multicolumn{2}{|c|}{ NR } \\
\hline Aspirin Intolerance & \multicolumn{3}{|c|}{ NR } & \multicolumn{2}{|c|}{ NR } & $5 / 20$ & $0 / 10$ & $8 / 15$ & $4 / 8$ & $6 / 30$ & $6 / 30$ & \multicolumn{2}{|c|}{ NR } \\
\hline $\begin{array}{l}\text { Nasal or sinus } \\
\text { surgery in history }\end{array}$ & $2 / 8$ & $6 / 8$ & $4 / 8$ & $7 / 7$ & $7 / 7$ & $15 / 20$ & $8 / 10$ & $13 / 15$ & $6 / 8$ & $16 / 30$ & $19 / 30$ & $54 / 54$ & $51 / 51$ \\
\hline \multirow[t]{2}{*}{ TPS } & $\begin{array}{c}6 \\
(4,5-7)\end{array}$ & $\begin{array}{c}5(3,5- \\
6,75)\end{array}$ & $\begin{array}{c}6 \\
(4,5-8)\end{array}$ & $\begin{array}{c}1,5 \\
(0,5-3)\end{array}$ & $\begin{array}{c}1,25 \\
(0-2,5)\end{array}$ & $\begin{array}{c}5,2 \\
(1,74)\end{array}$ & $\begin{array}{c}5,5 \\
(1,65)\end{array}$ & $\begin{array}{c}6 \\
(4-6)\end{array}$ & $\begin{array}{c}6 \\
(6-8)\end{array}$ & $\begin{array}{c}5,9 \\
(1,0)\end{array}$ & $\begin{array}{l}5,7 \\
(0,9)\end{array}$ & $\begin{array}{c}6,28 \\
(0,88)\end{array}$ & $\begin{array}{c}6,31 \\
(0,88)\end{array}$ \\
\hline & \multicolumn{5}{|c|}{ Median(range) } & \multicolumn{2}{|c|}{ Mean(SD) } & \multicolumn{2}{|c|}{ Median(IQR) } & \multicolumn{4}{|c|}{ Mean(SD) } \\
\hline \multirow[t]{2}{*}{$\begin{array}{l}\text { Lund-Mackay CT } \\
\text { scan score }\end{array}$} & \multirow{2}{*}{\multicolumn{3}{|c|}{ NR }} & & & & & $\begin{array}{c}17,5 \\
(14,5- \\
21)\end{array}$ & $\begin{array}{c}16,5 \\
(15,3- \\
21,3)\end{array}$ & $\begin{array}{l}18,6 \\
(5,0)\end{array}$ & $\begin{array}{l}18,7 \\
(5,5)\end{array}$ & & \\
\hline & & & & & & & & \multicolumn{2}{|c|}{ Median (IQR) } & \multicolumn{2}{|c|}{ Median (SD) } & & \\
\hline $\begin{array}{l}\text { \% Opacification } \\
\text { Baseline CT }\end{array}$ & & NR & & $\begin{array}{r}76 \% \\
\pm 6,9\end{array}$ & $\begin{array}{l}75,9 \% \\
\pm 6,1\end{array}$ & & & & & $\begin{array}{c}71,0 \\
(26,2)\end{array}$ & $\begin{array}{c}76,3 \\
(23,9)\end{array}$ & & \\
\hline & & & & Mea & sem & & & & & Mea & (SD) & & \\
\hline UPSIT & & NR & & $13 \pm 2,8$ & $19 \pm 3,4$ & & & $\begin{array}{c}12 \\
(10-23)\end{array}$ & $\begin{array}{c}12 \\
(10-13)\end{array}$ & $\begin{array}{l}12,8 \\
(8,3)\end{array}$ & $\begin{array}{l}12,8 \\
(8,3)\end{array}$ & & \\
\hline & & & & Mea & sem & & & Medi & (IQR) & Mea & (SD) & & \\
\hline NPIF & & NR & & $\begin{array}{c}93,3 \\
(53,3- \\
173,3)\end{array}$ & $\begin{array}{c}133,3 \\
(113,3- \\
156,7)\end{array}$ & & & & & $\begin{array}{c}98,4 \\
(48,5)\end{array}$ & $\begin{array}{l}109,2 \\
(46,8)\end{array}$ & $101(67)$ & $102(65)$ \\
\hline & & & & Mean & range & & & & & Mea & (SD) & & \\
\hline $\begin{array}{l}\text { Nasal congestion or } \\
\text { obstruction }\end{array}$ & & NR & & & & $\begin{array}{l}2,15 \\
(0,75)\end{array}$ & $\begin{array}{c}2,4 \\
(0,70)\end{array}$ & & & $\begin{array}{c}1,7(0,7) \\
\text { AM 1,6 } \\
(0,8) \\
\text { PM }\end{array}$ & $\begin{array}{c}1,7(0,7) \\
\text { AM } 1,6 \\
(0,7) \\
\text { PM }\end{array}$ & $\begin{array}{c}7,90 \\
(7,23- \\
8,56)\end{array}$ & $\begin{array}{c}8,01 \\
(7,32- \\
8,69)\end{array}$ \\
\hline Loss of smell & & NR & & & & $\begin{array}{l}2,65 \\
(0,59)\end{array}$ & $\begin{array}{c}2,4 \\
(0,84)\end{array}$ & & & $\begin{array}{c}2,4(0,9) \\
\text { AM } 2,4 \\
(0,9) \\
\text { PM }\end{array}$ & $\begin{array}{c}2,8(0,5) \\
\text { AM } 2,8 \\
(0,5) \\
\text { PM }\end{array}$ & $\begin{array}{c}9,06 \\
(8,43- \\
9,69)\end{array}$ & $\begin{array}{c}9,10 \\
(8,45- \\
9,75)\end{array}$ \\
\hline Anterior Rhinorrhea & & NR & & & & $1,5(0,89)$ & $1,8(0,79)$ & & & $\begin{array}{c}1,0(0,9) \\
\text { AM } 1,0 \\
(0,9) \\
\text { PM }\end{array}$ & $\begin{array}{c}1,1(0,8) \\
\text { AM } 1,2 \\
(0,7) \\
\text { PM }\end{array}$ & $\begin{array}{c}6,24 \\
(5,57-6 \\
91)\end{array}$ & $\begin{array}{c}6,19 \\
(5,50 \\
6,8)\end{array}$ \\
\hline & & & & & & & & Me & (SD) & & & Mea & (IQR) \\
\hline $\begin{array}{l}\text { SNOT-20 Mean } \\
\pm \text { sem }\end{array}$ & & NR & & $\begin{array}{l}45,7 \\
\pm 5,6\end{array}$ & $\begin{array}{l}46,0 \\
\pm 11\end{array}$ & & & & & & & & \\
\hline SNOT-22 Mean (SD) & & NR & & & & & & & & $\begin{array}{c}41,4 \\
(18,2)\end{array}$ & $\begin{array}{c}40,6 \\
(19,9)\end{array}$ & $\begin{array}{l}51,05 \\
(17,0)\end{array}$ & $\begin{array}{c}49,5 \\
(19,0)\end{array}$ \\
\hline & & & & & & & & Physic & Health & & & & \\
\hline SF-36 & & NR & & $\begin{array}{c}61,8 \\
\pm 15,2\end{array}$ & $\begin{array}{c}67,6 \\
\pm 10,5\end{array}$ & & & $\begin{array}{c}48 \\
(45-52)\end{array}$ & $\begin{array}{c}50 \\
(45,5- \\
52,8)\end{array}$ & & & & \\
\hline $\begin{array}{l}\text { Blood Eosinophils (/ } \\
\mu \mathrm{L} \text {, median (IQR) }\end{array}$ & $\begin{array}{c}210 \\
(180- \\
350)\end{array}$ & $\begin{array}{c}240 \\
(180- \\
460)\end{array}$ & $\begin{array}{c}170 \\
(130- \\
280)\end{array}$ & & & & & $\begin{array}{c}390 \\
(313- \\
698)\end{array}$ & $\begin{array}{c}475 \\
(365- \\
630)\end{array}$ & $\begin{array}{c}360 \\
(250- \\
470)\end{array}$ & $\begin{array}{c}320 \\
(180- \\
490)\end{array}$ & & \\
\hline $\begin{array}{l}\text { Serum ECP }(\mu \mathrm{g} / \mathrm{L}) \\
\text { median }(\mathrm{IQR})\end{array}$ & $\begin{array}{c}15,8 \\
(11,2- \\
35,7)\end{array}$ & $\begin{array}{l}13,5 \\
(9,9- \\
31,6)\end{array}$ & $\begin{array}{l}10,7 \\
(5,2- \\
34,7)\end{array}$ & & & & & $\begin{array}{c}31 \\
(14-56)\end{array}$ & $\begin{array}{c}32 \\
(20-91)\end{array}$ & & & & \\
\hline
\end{tabular}




\begin{tabular}{|c|c|c|c|c|c|c|c|c|c|c|}
\hline \multirow[b]{2}{*}{$\begin{array}{l}\text { Serum SOL } \\
\text { IL-5Ra }(\mathrm{pg} / \mathrm{ml}) \\
\text { median(IQR) }\end{array}$} & \multicolumn{3}{|c|}{$\begin{array}{l}\text { Gevaert et al. } \\
\qquad(2006)\end{array}$} & \multirow{2}{*}{$\begin{array}{c}\text { Pinto et al. } \\
\text { (2010) } \\
\text { NR }\end{array}$} & \multirow{2}{*}{$\begin{array}{c}\text { Gevaert et al. } \\
\text { (2011) } \\
\text { NR }\end{array}$} & \multicolumn{2}{|c|}{$\begin{array}{c}\text { Gevaert et al. } \\
\text { (2013) }\end{array}$} & \multicolumn{2}{|c|}{$\begin{array}{l}\text { Bachert et al. } \\
\qquad(2016)\end{array}$} & \multirow{2}{*}{$\begin{array}{c}\text { Bachert et al. } \\
\text { (2017) } \\
\text { NR }\end{array}$} \\
\hline & $\begin{array}{c}464,6 \\
(384- \\
695)\end{array}$ & $\begin{array}{l}737 \\
(436- \\
2263)\end{array}$ & $\begin{array}{c}547 \\
(406- \\
756)\end{array}$ & & & $\begin{array}{c}258 \\
(207- \\
332)\end{array}$ & $\begin{array}{c}292 \\
(249- \\
413)\end{array}$ & & & \\
\hline $\begin{array}{l}\text { Nasal Secretion ECP } \\
(\mu \mathrm{g} / \mathrm{L}) \text { median (IQR) }\end{array}$ & $\begin{array}{c}350,7 \\
(76,6- \\
1519,6)\end{array}$ & $\begin{array}{c}283,1 \\
(196,8- \\
932,1)\end{array}$ & $\begin{array}{l}344,1 \\
(74,2- \\
867,3)\end{array}$ & NR & NR & $\begin{array}{c}362 \\
(176- \\
653)\end{array}$ & $\begin{array}{l}994 \\
(591- \\
1888)\end{array}$ & & & NR \\
\hline $\begin{array}{l}\text { Nasal Secretion } \\
\text { SOL IL-5Ra (pg/ml) } \\
\text { median (IQR) }\end{array}$ & $\begin{array}{l}2243 \\
(779- \\
6461)\end{array}$ & $\begin{array}{l}2198 \\
(592- \\
7103)\end{array}$ & $\begin{array}{l}1385 \\
(677- \\
3766)\end{array}$ & NR & NR & $\begin{array}{c}494 \\
(169- \\
1128)\end{array}$ & $\begin{array}{l}1199 \\
(757- \\
2771)\end{array}$ & & & NR \\
\hline $\begin{array}{l}\text { Nasal Secretion IL-5 } \\
\text { (pg/ml) median } \\
\text { (IQR) }\end{array}$ & $\begin{array}{c}39,5 \\
(24,5- \\
292,7)\end{array}$ & $\begin{array}{c}45,2 \\
(26,3- \\
61,1)\end{array}$ & $\begin{array}{c}34,9 \\
(24,6- \\
138,0)\end{array}$ & NR & NR & $\begin{array}{c}66(24- \\
105)\end{array}$ & $\begin{array}{l}90(29- \\
122)\end{array}$ & & & NR \\
\hline $\begin{array}{l}\text { Total serum IgE, IU/ } \\
\text { mlmedian (IQR) }\end{array}$ & & NR & & NR & NR & $\begin{array}{c}108(39- \\
130)\end{array}$ & $\begin{array}{c}84(71- \\
148)\end{array}$ & $\begin{array}{c}87(47- \\
185)\end{array}$ & $\begin{array}{l}101(37- \\
254)\end{array}$ & NR \\
\hline
\end{tabular}

TRG: treatment group, CRG: control group, TRG1: reslizumab 1mg/kg, TRG2 reslizumab 3mg/kg, NR: non reported, TPS: total nasal endoscopic polyp score, CT: computed tomography, SNOT: Sino-nasal Outcome Test, SF-36: 36-Item Short Form Survey, UPSIT: University of Pennsylvania Smell Identification Test, PNIF: Peak Nasal Inspiratory Flow, IgE: immunoglobulin E, IL: interleukin, SOL IL-5Ra: secreted interleukin-5 receptor alpha subunit, ECP: eosinophil cationic protein, SD: standard deviation, IQR: interquartile range, sem: standard error of mean, pg: pictograms, $\mu$ g: micrograms ml:milliliters, L: litres IU: international unit, AM: before noon, PM: after noon, y:years

score were computed for the same purpose ${ }^{(22)}$.

Pinto et al. ${ }^{(17)}$ showed that omalizumab managed to reduce significantly the inflammation compared to the placebo group. However, the median change of sinus opacification (pre-treatment minus post-treatment) across groups was not statistically significant $(p<0,391)$. On the contrary, Gevaert et al. ${ }^{(19)}$ showed that omalizumab resulted in significant reduction of Lund-Mackay scores on radiologic imaging $(p=0,04)$.

Mepolizumab was effective in improving CT scores in more than half of the treated subjects as opposed to less than $20 \%$ in the placebo group $(p=0,06, p=0,024, p=0,049$ for the 3 different raters of the study) $)^{(20)}$.Finally, in Bachert et al. ${ }^{(22)}$ study a significant improvement from baseline with the use of dupilumab was observed not only in percentage of maxillary sinus opacification $(p<0,001)$ but also in Lund-Mackay total score $(p<0,001)$.

\section{Quality of Life measures}

SNOT-20, SNOT-22, SF-36 and Rhinosinusitis Outcome Measurement Instrument (RSOM-31) were included in the secondary measures of most of the six studies (Table 4).

In particular, Pinto et al. ${ }^{(19)}$ showed that although omalizumab appeared to improve SNOT-20 scores significantly in the omalizumab as compared to the placebo group, the net change between the two groups was not statistically significant $(p<0,78)$. Concerning the SF-36, vitality was the only domain in which a statistically significant improvement was observed with the use of omalizumab $(p<0,05)$.

In Gevaert et al. ${ }^{(21)}$ study, omalizumab appeared to be effective in improving significantly both the SF-36 (physical health) $(p=0,02)$ and sleep and general symptoms of RSOM-31 $(p=0,02)$. Finally, SNOT-22 was improved significantly by the use of both dupilumab $^{(22)}$ and mepolizumab ${ }^{(23)}(p<0,001$ and $p=0,005$, respectively) $)^{(23)}$.

\section{Nasal airflow (PNIF) and olfaction (UPSIT)}

Change in PNIF was the subject of research in four of the included studies (Table 4). In Pinto et al. study ${ }^{(19)}$, omalizumab was not found to be effective in improving PNIF as the net change across the two groups was not statistically significant $(p<0,31)$. Gevaert et al. ${ }^{(20)}$ reported a reduction in nasal obstraction as patients in the mepolizumab group showed better values from baseline in PNIF as compared to placebo group but the results were not statistically significant $(p=0,10)$. On the contrary, the mean difference between mepolizumab and control group in PNIF values was statisticallly significant $(p=0,027$, in the second mepolizumab study ${ }^{(23)}$. At last, Bachert et al. ${ }^{(22)}$ reported a statistically significant mean difference in PNIF for dupilumab group vs placebo $(p=0,002)$.

Three RCTs studied the effectiveness of monoclonal antibodies in olfaction and the outcome was the change in UPSIT sco$\mathrm{re}^{(19,22,23)}$. Neither omalizumab ${ }^{(19)}$ nor mepolizumab ${ }^{(23)}$ was found to yield a statistically significant benefit concerning UPSIT score ( $p<0,31$ and $p=0,233$, respectively). On the contrary, dupilumab proved to be effective and lead to a statistically significant improvement as compared to placebo $(p<0,001)^{(22)}$.

\section{Type $\mathbf{2}$ helper T-cell-associated biomarkers}

Concerning changes in Type 2 Helper T-cell-Associated Biomarkers (Table 4), despite the significant decrease of eosinophil counts which was reported in both treatment groups with the use of reslizumab(18), a rebound eosinophilia was appeared at week 24 and week 32 in $1 \mathrm{mg} / \mathrm{kg}$ and $3 \mathrm{mg} / \mathrm{kg}$ treatment groups, 


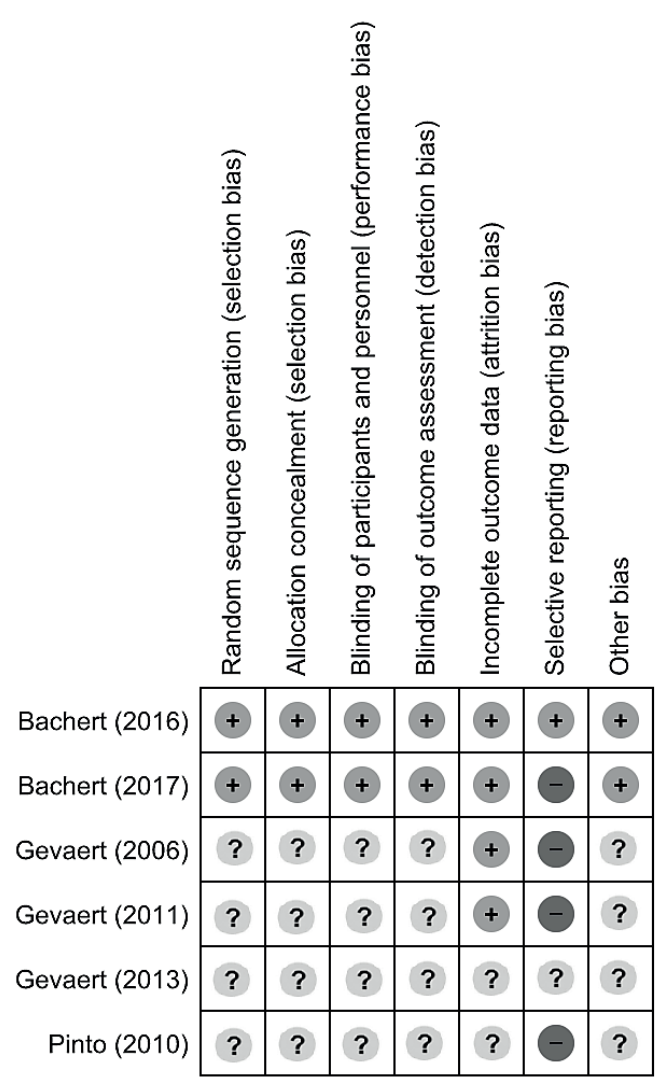

Figure 2. Risks of bias of individual RCTs.

respectively. The use of mepolizumab lead to a significant reduction in blood eosinophil counts compared to placebo group and in this case no rebound eosinophilia effect was reported in any of the two RCTs ${ }^{(20,23)}$.

No statistically significant decrease in eosinophil counts was also reported for both dupilumab and placebo group in Bachert et al. ${ }^{(22)}$ study $(p=0,78)$. Finally, in Pinto et al. ${ }^{(19)}$ study omalizumab did not show a significant difference in eosinophils in nasal lavage in either group $(p<0,47)$. Some others biomarkers included in our study are serum IL-5Ra, nasal IL-5Ra, serum ECP, nasal $E C P$. The changes in values from baseline were studied in two of the six studies. In particular, reslizumab lead to a statistically significant decrease in all these biomarkers in both treatment groups $^{(18)}$. Lastly, with the exception of nasal ECP $(p=0,26)$, all of the aformentioned biomarkers were significantly decreased by the use of mepolizumab as compared to placebo ${ }^{(20)}$.

\section{Safety and adverse events}

Five RCTs reported a wide variety of adverse events the majority of them were negligible with the most common being upper respiratory tract infections (common cold and nasopharyngitis included). A total number of eight serious adverse events were reported in only two of the included studies none of which was deemed to be associated with the monoclonal antibody therapy (Table 5).

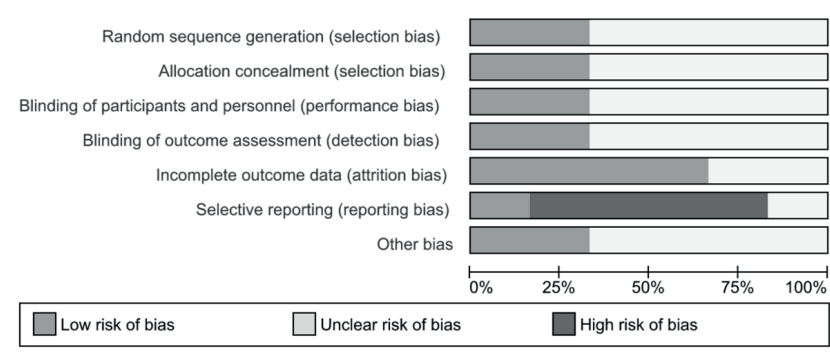

Figure 3. Overal risk of bias of RCTs.

\section{Discussion}

Since the advent of monoclonal antibodies for the management of several inflammatory conditions, a number of studies have been conducted proposing the potential use of these agents in the treatment of CRSwNP. This is the first systematic review assessing the efficacy of the three main categories of monoclonal antibodies in the treatment of chronic rhinosinusitis showing positive results in at least five of the six included studies for most domains. Overall, this systematic review supports the concept that omalizumab could be a promising alternative option for a subgroup of CRSwNP patients with asthma, recurrence of polyps after surgery and high levels of serum IgE, despite the fact that improvements in most primary and secondary outcomes were shown only in one of the two RCTs. Moreover, the results of the three RCTs with reslizumab and mepolizumab were especially encouraging regarding the incorporation of anti-IL-5 mAb as a treatment option of specific CRSwNP. Finally, dupilumab showed a clear benefit in most of main and secondary outcomes and may be included in the treatment options in patients with CRSwNP refractory to standard treatment with intranasal corticosteroids especially in those with comorbid asthma.

Omalizumab is the type of biologic therapy that has been investigated more than any other. The first report for the potential efficacy of this agent in patients with CRSwNP was published by Penn et al. ${ }^{(24)}$ in 2007. In this pilot study, 4 patients with nasal polyposis and comorbid asthma reported a statistically significant difference between the pre and post omalizumab treatment endoscopic scores, which were not combined with statistically relevant differences in their CT scores. This study was followed by a number of other small studies that confirmed the potential clinical benefit of omalizumab ${ }^{(25-27)}$. The latter provide low strong evidence and do not allow for definitive conclusions despite their encouraging results. Two systematic reviews have also pointed out the need for further assessment of the effectiveness of anti-lgE therapy in these patients ${ }^{(28,29)}$. Aside from the proof of clinical benefit, several other obstacles have to be overcome for omalizumab to be officially incorporated in the standard therapy of CRSwNP. First, cost-effectiveness has not been assessed in any of the aforementioned studies despite its being a crucial 
Table 4. Summary of study results.

\begin{tabular}{|c|c|c|c|c|c|c|c|}
\hline & \multirow[t]{2}{*}{ TPS } & \multicolumn{2}{|c|}{ CT } & \multicolumn{4}{|c|}{ Quality of life Measures } \\
\hline & & $\begin{array}{l}\text { Percent opacification } \\
\text { on CT }\end{array}$ & Lund Muckay score & \multicolumn{2}{|c|}{ SNOT-20 or SNOT-22 } & \multicolumn{2}{|c|}{ SF-36 } \\
\hline $\begin{array}{l}\text { Gevaert } \\
\text { et al. (2006) }\end{array}$ & $\begin{array}{l}\text { TRG1: decrease up to } 12 \mathrm{w} \text { in } 5 / 8 \\
\text { patientsTRG2: decrease up to } 4 \mathrm{w} \text { in } \\
4 / 8 \text { patients }\end{array}$ & NR & NR & \multicolumn{2}{|c|}{ NR } & \multicolumn{2}{|c|}{ NR } \\
\hline $\begin{array}{l}\text { Pinto et al. } \\
\text { (2010) }\end{array}$ & $\begin{array}{l}\text { No significant changes for either } \\
\text { group. Net change TRG } 0 \text {, CRG }-0,5 \text {, } \\
p<0,58\end{array}$ & $\begin{array}{l}\text { TRG( median pre } 76,1 \% \text {, } \\
\text { post } 60 \%, p<0,043) \text { CRG( } \\
\text { median pre } 75,9 \% \text {,post } \\
66,1 \%, p<0,463 \text { )Magnitude } \\
\text { of change across treatment } \\
\text { groups ( median change } \\
\text { TRG } 11,9 \% \text {, CRG } 5,9 \% \text {, } \\
p<0,391 \text { ) }\end{array}$ & NR & \multicolumn{2}{|c|}{$\begin{array}{l}\text { Change from baseline( } \\
\text { TRG: }-1,05 \text { CRG:- } 0,20 \text { ) } \\
\text { Net magnitude between } \\
\text { groups, } p<0,78\end{array}$} & \multicolumn{2}{|c|}{$\begin{array}{l}\text { No significant differences } \\
\text { for any domain across } \\
\text { groups except for vitality } \\
\text { (omalizumab 9,4 placebo } \\
12,5 p<0,05 \text { ) }\end{array}$} \\
\hline $\begin{array}{l}\text { Gevaert } \\
\text { et al. (2011) }\end{array}$ & $\begin{array}{l}\text { Change from baseline (8w)TRG } \\
-1,30 \text { (SD } 1,72 \text { )CRG } 0,00 \text { (SD 0,94) } \\
\text { Treatment dif. }-1,30 \text { (SD } 1,51 \text { ) } \\
p=0,028 \text { Percentage improvement } \\
60 \% \text { vs } 10 \% \text { odds ratio: } 13,5 p=0,018\end{array}$ & $\begin{array}{l}\text { Improvement in more } \\
\text { than half of the TRG group } \\
\text { and less than } 20 \% \text { of the } \\
\text { CRG group Rater } A: 6 \\
p=0,06 \text { Rater } B: 11 p=0,024 \\
\text { Rater } C: 9 p=0,049\end{array}$ & NR & \multicolumn{2}{|c|}{ NR } & \multicolumn{2}{|c|}{ NR } \\
\hline $\begin{array}{l}\text { Gevaert } \\
\text { et al. (2013) }\end{array}$ & $\begin{array}{l}\text { Change from baseline }(16 w) \text { TRG : } \\
-2,67 p=0,01 \text { CRG: }-0,12 p=0,99\end{array}$ & NR & $\begin{array}{l}\text { TRG from } 17,6 \text { to } 13,6 \\
p=0,02 \text { CRG from } 17,8 \text { to } \\
18,3 p=0,10 \text { Comparing } \\
\text { both groups: improve- } \\
\text { ment in TRG } p=0,04\end{array}$ & \multicolumn{2}{|c|}{ NR } & \multicolumn{2}{|c|}{$\begin{array}{l}\text { Improvement ofPhysical } \\
\text { Health TRG : } p=0,02 \text { CRG: } \\
p=0,75\end{array}$} \\
\hline $\begin{array}{l}\text { Bachert } \\
\text { et al. (2016) }\end{array}$ & $-1,6(-2,4$ to $-0,7) p<0,001$ & \multicolumn{2}{|c|}{$\begin{array}{l}-32,2(-43,1 \text { to }-21,4) p<0,001-8,8(-11,1 \text { to }-6,6) p<0,001 \\
\text { Abs dif. from TRG vs CRG LS Mean }(95 \% \mathrm{Cl})\end{array}$} & \multicolumn{2}{|c|}{$\begin{array}{l}-18,1(-25,6 \text { to }-10,6) \\
p<0,001\end{array}$} & \multicolumn{2}{|c|}{ NR } \\
\hline \multirow[t]{2}{*}{$\begin{array}{l}\text { Bachert } \\
\text { et al. (2017) }\end{array}$} & $\begin{array}{l}\text { Significant difference between CRG } \\
\text { and TRG (w: } 9-25 \text { ) }\end{array}$ & NR & NR & \multicolumn{2}{|c|}{$\begin{array}{l}\text { Abs dif. from TRG vs CRG } \\
\text { LS Mean }(95 \% \mathrm{Cl}) 13.2 \\
(-22.2 \text { to }-4.22) p=0,005\end{array}$} & \multicolumn{2}{|c|}{ NR } \\
\hline & $\begin{array}{l}\text { Cellular inflammation-Eosi- } \\
\text { nophil count }\end{array}$ & PNIF & UPSIT & $\begin{array}{l}\text { Serum } \\
\text { IL-5Ra }\end{array}$ & $\begin{array}{l}\text { Nasal } \\
\text { IL-5Ra }\end{array}$ & $\begin{array}{l}\text { Serum } \\
\text { ECP }\end{array}$ & $\begin{array}{l}\text { Nasal } \\
\text { ECP }\end{array}$ \\
\hline $\begin{array}{l}\text { Gevaert } \\
\text { et al. (2006) }\end{array}$ & $\begin{array}{l}\text { Significant decrease in both TRG } \\
\text { groups as compared with the } \\
\text { CRG. Returned to baseline levels } \\
\text { at week } 12 \text {. Significant rebound at } \\
\text { week } 24 \text { and } 32 \text { for TRG1 and TRG2 } \\
\text { respectively. }\end{array}$ & NR & NR & $\begin{array}{l}\text { Significant } \\
\text { CRG group }\end{array}$ & ase in bot & TRGcompar & ith the \\
\hline $\begin{array}{l}\text { Pinto } \\
\text { et al. (2010) }\end{array}$ & $\begin{array}{l}\text { Median change in } \%: \text { TRG }-2, \text { CRG }-9 \text {, } \\
p<0,47 \text { (Nasal lavage) }\end{array}$ & $\begin{array}{l}\text { Net change across groups } \\
\text { (median: TRG:-3, } 1 \text { CRG: } 11,3 \\
\mathrm{p}<0,31 \text { ) }\end{array}$ & $\begin{array}{l}\text { Net change: TRG } 3 \text { CRG } 4 \\
p<0,31)\end{array}$ & & & $\mathrm{R}$ & \\
\hline $\begin{array}{l}\text { Gevaert } \\
\text { et al. (2011) }\end{array}$ & $-332(241) p<0,01$ & $1,047(1,602) p=0,10$ & NR & $\begin{array}{c}-9,255 \\
(7,520) \\
p<0,001\end{array}$ & $\begin{array}{c}0,30 \\
p=0,01\end{array}$ & $\begin{array}{l}-2,124 \\
(2,514) \\
p=0,022\end{array}$ & $\begin{array}{c}0,77 \\
p=0,26\end{array}$ \\
\hline & \multicolumn{7}{|c|}{ Change from baseline mean (SD) } \\
\hline $\begin{array}{l}\text { Gevaert } \\
\text { et al. (2013) }\end{array}$ & NR & NR & NR & & & $\mathrm{R}$ & \\
\hline \multirow[t]{2}{*}{$\begin{array}{l}\text { Bachert } \\
\text { et al. (2016) }\end{array}$} & $-4,4(-36,1$ to 27,2$) p=0,78$ & $33,1(12,7$ to 53,5$) p=0,002$ & $\begin{array}{l}14,8(10,9 \text { to } 18,7) \\
p<0,001\end{array}$ & NR & & & \\
\hline & \multicolumn{7}{|c|}{ Abs dif. from TRG vs CRG LS Mean $(95 \% \mathrm{CI})$} \\
\hline $\begin{array}{l}\text { Bachert } \\
\text { et al. (2017) }\end{array}$ & $\begin{array}{l}\text { TRG: decrease from a geometric } \\
\text { mean (SD log) of } 500 \text { cells/ } \mu \mathrm{l}(0,712) \\
\text { at baseline to } 50 \text { cells/ } \mu \mathrm{l} \text { at w } 25 \mathrm{CRG} \text { : } \\
\text { none }\end{array}$ & $\begin{array}{l}\text { Abs dif. from TRG vs CRG LS } \\
\text { Mean }(95 \% \mathrm{Cl}) 26,7(3,1 \text { to } \\
50,2) p=0,027\end{array}$ & NR & & & & \\
\hline
\end{tabular}

TRG: treatment group, CRG: control group, TRG1: reslizumab 1mg/kg, TRG2 reslizumab 3mg/kg, NR: non reported, TPS: total nasal endoscopic polyp score, CT: computed tomography, SNOT: Sino-nasal Outcome Test, SF-36: 36-Item Short Form Survey, UPSIT: University of Pennsylvania Smell Identification Test, PNIF: Peak Nasal Inspiratory Flow, IL: interleukin, SOL IL-5Ra: secreted interleukin-5 receptor alpha subunit, ECP: eosinophil cationic protein, Abs dif: absolute difference, LS: least squares, Cl: confidence interval, SD: standard deviation, IQR: interquartile range, $\mu$ l: microliter, w: weeks 
Table 5. Adverse events reported in the treatment and control groups during the study.

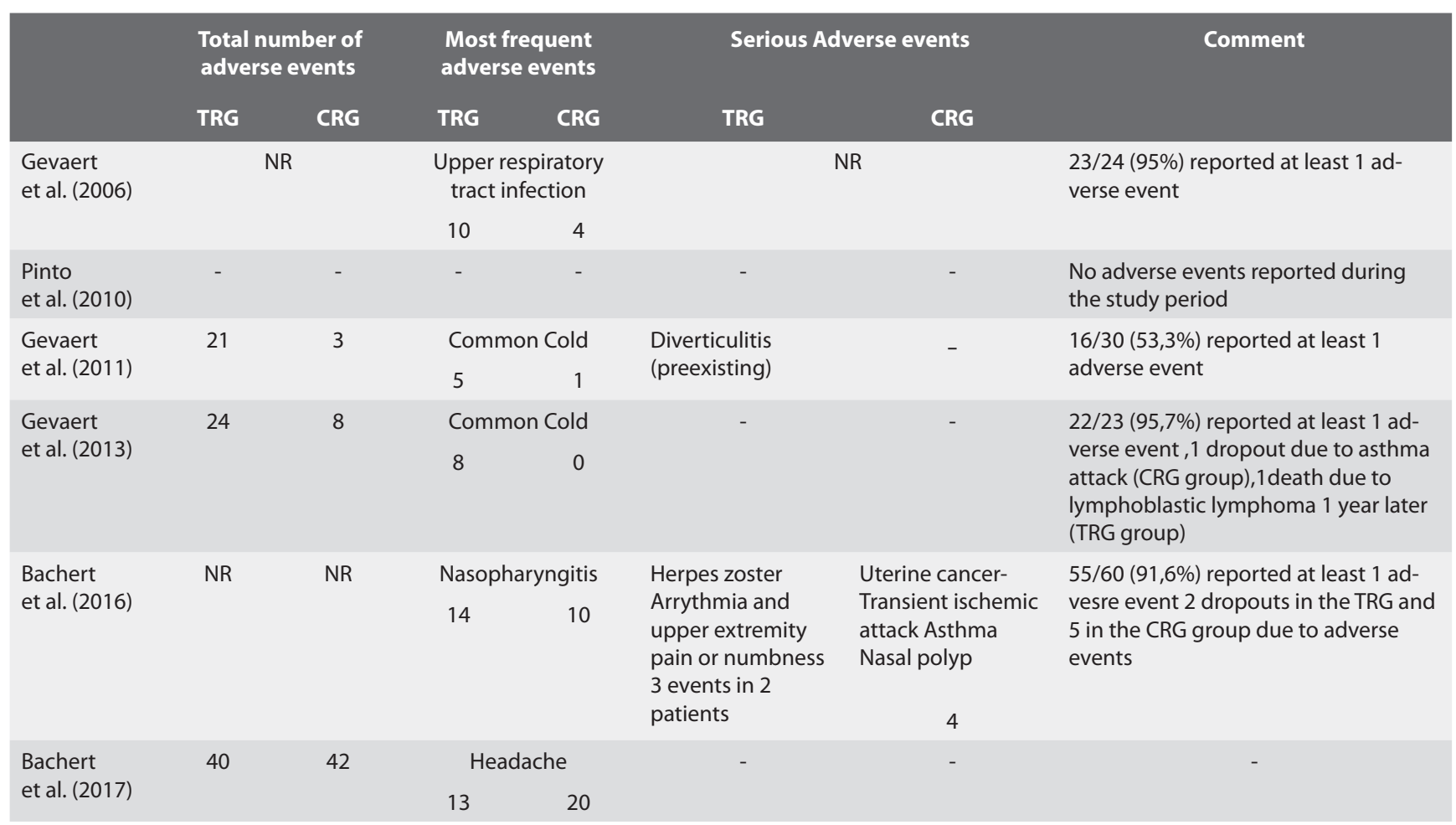

TRG: treatment group, CRG: control group, NR: non reported.

factor in the management of this disease. Second, there is not sufficient data regarding the safety of omalizumab; malignancy and anaphylactic reactions are side effects most strongly linked with this biologic agent so far $^{(30,31)}$. However, all in all, omalizumab seems to be a safe and tolerable treatment option in patients with moderate-to-severe or severe allergic asthma ${ }^{(32,33)}$, a point that is in line with the results of this systematic review.

Based on the present systematic review, anti-IL-5 therapy can be extended to CRSWNP patients ${ }^{(18,20,23)}$. Supporting the results of our systematic review, Castro et al. ${ }^{(34)}$ conducted an RCT assessing the efficacy of reslizumab in patients with poorly controlled eosinophilic asthma, showing that the subgroup of patients with comorbid nasal polyposis reported a statistically significant improvement in Asthma Control Questionnaire scores for the treatment in comparison to the placebo group (-1 vs $-0,1$ $p=0,0119)$. Lastly, benralizumab, a humanized afucosylated IgG1 k mAb that targets the a subunit of the receptor to IL-5, has been introduced, enhancing eosinophil-depleting activity when compared to neutralizing monoclonal antibody directed against IL-5 ${ }^{(35)}$. An RCT condacted by Laviolette et al. ${ }^{(36)}$ showed that benralizumab lead to a reduction in eosinophil count in the airway mucosa, sputum, bone marrow, and peripheral blood of patients with asthma in comparison to placebo. In addition, a 74\% reduction in blood basophil count was also presented showing that this agent could offer a potential benefit in CRSwNP patients who present with elevated levels of this type of cells. However, no study assessing the efficacy of this novel monoclonal antibody in patients with CRSwNP has been conducted so far.

Taking into account the importance of IL-4 and IL-13 cytokines in type 2 inflammatory responses, several studies with monoclonal antibodies, that inhibit either IL-4 or IL-13 have been designed, investigating their efficacy in patients with asthma, with their results however being ambiguous ${ }^{(37)}$. Dupilumab acts by blocking both cytokines by targeting the $\alpha$ chain of IL-4Ra which is common in both IL-4 and IL-13 and can lead to a more comprehensive inhibition of the type 2 inflammatory pathway. It has been shown to be of clinical benefit in patients suffering from allergic asthma and atopic dermatitis ${ }^{(16,17)}$. Bachert et al. showed especially encouraging results for the use of dupilumab in patients with CRSwNP as almost all primary and secondary outcomes were met. The results were consistent with those of the aforementioned studies confirming the common type 2 inflammatory mechanisms in these disorders ${ }^{(22)}$. Consistency was also found with the results of both mepolizumab ${ }^{(20)}$ and omalizumab $^{(21)}$ studies, however no conclusion about the superiority of the one monoclonal antibody over the other can be inferred as all included studies in this systematic review investigated the efficacy of each monoclonal antibody separately against 
placebo.

The results of this systematic review are liable to certain limitations. First, although we decided to include only RCTs for the sake of the greater power of our research, the low sample size, the short study period, the incomplete reporting data in the majority of them in combination with the heterogeneity among study designs made it difficult to compare the effects of the interventions. Furthermore, we conducted a comprehensive search without language or time limitation in several bibliographic databases and the probability to have missed potential eligible studies is low. However, through our search, we retrieved studies whose results were not available either because their data was still being analyzed ${ }^{(38)}$ or they had not been completed so $\mathrm{far}^{(39-41)}$. This fact could have an impact on this systematic review or radically change our view regarding this issue in the foreseeable future.

Failure to treat this challenging disease using conservative methods inevitably leads to surgery. Even endoscopic surgery, however, is not always successful and repetition of surgery might be mandatory. This state of affairs takes its toll on the national health service, from a financial point of view, and on the patient, from a psychological point of view. Despite the encouraging results of this systematic review, the paucity of large RCTs, the several methodological limitations of the included studies, for example, short treatment period and especially small sample size, are important factors that should not be underestimated in drawing definitive conclusions. Furthermore, the high cost of these agents should be taken into account, when deciding on optimal treatment of CRSwNP(42). Cost-effectiveness of the aforementioned monoclonal antibodies has only been assessed for the conditions, for whom these agents have been approved of. In particular, two studies have shown that benefit outweighs the cost of omalizumab and dupilumab treatment of asthma and atopic dermatitis ${ }^{(43,44)}$. It has been found, however, that mepolizumab's cost must be reduced by at least $60 \%$ for its use to become cost-effective ${ }^{(45)}$. No data has been presented regarding cost-effectiveness of these monoclonal antibodies for the treatment of CRSwNP, making it mandatory that further studies evaluate this gravely important aspect. Finally, future research efforts should be directed towards assessing further biomarkers of Th2 inflammatory pathways, which will reflect the response to these novel treatments. A recently studied such biomarker is periostin, the levels of which both in serum and nasal secretions have been found to correlate with the response to anti-inflammatory treatment for CRSwNP(46).

\section{Conclusions}

Targeting IgE, IL-5 and IL-4/IL-13 cytokine pathways constitutes a novel therapy in patients suffering from CRSwNP. Despite the small number of studies, with their small sample size and several limitations, their results are really encouraging and biologic therapy seems to be safe and well tolerated. However, high-quality trials designed to assess these therapeutic alternatives for this specific subpopulation of patients with CRSwNP refractory to standard treatment are called for.

\section{Acknowledgements}

This study was not supported by any company or persons other than the authors.

\section{Authorship contribution}

NT: Literature search, data extraction, analysis and manuscript production, JG: Design, analysis and manuscript review, DD: Literature search, data extraction and analysis, IK: Manuscript review and preparation, KM: Design and expert manuscript review

\section{Conflict of interest}

None to declare.

\section{References}

1. Hirsch AG, Stewart WF, Sundaresan AS, Young AJ, Kennedy TL, Scott Greene J, et al. Nasal and sinus symptoms and chronic rhinosinusitis in a population-based sample. Allergy. 2017;72(2):274-81.

2. Hastan D, Fokkens WJ, Bachert C, Newson RB, Bislimovska J, Bockelbrink $A$, et al. Chronic rhinosinusitis in Europe - An underestimated disease. A GA2LEN study. Allergy Eur J Allergy Clin Immunol. 2011;66(9):1216-23.

3. Fokkens W, Lund V, Mullol J. European Position Paper on Rhinosinusitis and Nasal Polyps. Rhinology. 2007;(20):1-136.

4. Akdis CA, Bachert C, Cingi C, Dykewicz MS, Hellings PW, Naclerio RM, et al. Endotypes and phenotypes of chronic rhinosinusitis: a PRACTALL document of the
European Academy of Allergy and Clinical Immunology and the American Academy of Allergy, Asthma \&amp; Immunology. J Allergy Clin Immunol. $2013 ; 131$ (6):1479-90.

5. Smith KA, Orlandi RR, Rudmik L. Cost of adult chronic rhinosinusitis: A systematic review. Laryngoscope. 2015;125(7):1547-56.

6. Larsen K. The clinical relationship of nasal polyps to asthma. Allergy Asthma Proc:; 17(5):243-9.

7. Settipane GA, Chafee FH. Nasal polyps in asthma and rhinitis. A review of 6,037 patients. J Allergy Clin Immunol. 1977;59(1):17-21.

8. Bachert C, Zhang N, Holtappels G, De Lobel $L$, van Cauwenberge $P$, Liu S, et al. Presence of IL-5 protein and IgE antibodies to staphylococcal enterotoxins in nasal polyps is associated with comorbid asthma. J Allergy
Clin Immunol. 2010;126(5):962-968; 8 e1-6. 9. Van Zele T, Holtappels G, Gevaert P, Bachert C. Differences in initial immunoprofiles between recurrent and nonrecurrent chronic rhinosinusitis with nasal polyps. Am J Rhinol Allergy. 2014;28(3):192-8.

10. Shih-Lung $\mathrm{C}$, Lin $\mathrm{C}-\mathrm{H}$. A review of omalizumab for the management of severe asthma. Drug Des Devel Ther. 2016; Volume 10:2369-78.

11. Bachert C, Gevaert P, Holtappels G, Cuvelier C, van Cauwenberge P. Nasal polyposis: from cytokines to growth. Am J Rhinol; 14(5):279-90.

12. Hamilos, Leung, Huston, Kamil, Wood, Hamid. GM-CSF, IL-5 and RANTES immunoreactivity and $\mathrm{mRNA}$ expression in chronic hyperplastic sinusitis with nasal polyposis (NP).Clin Exp Allergy. 1998 Sep;28(9):1145- 
52.

13. Bachert C, Wagenmann M, Hauser $U$, Rudack C. IL-5 synthesis is upregulated in human nasal polyp tissue. J Allergy Clin Immunol. 1997; 99(6 Pt 1):837-42.

14. Shrimanker R, Pavord ID. Interleukin-5 Inhibitors for Severe Asthma: Rationale and Future Outlook. BioDrugs. 2017;31(2):93103.

15. Shirley M. Dupilumab: First Global Approval. Drugs. 2017;77(10):1115-21.

16. Wenzel S, Ford L, Pearlman D, Spector S, Sher L, Skobieranda F, et al. Dupilumab in Persistent Asthma with Elevated Eosinophil Levels. N Engl J Med. 2013;368(26):2455-66.

17. Beck LA, Thaçi D, Hamilton JD, Graham NM, Bieber T, Rocklin R, et al. Dupilumab Treatment in Adults with Moderate-toSevere Atopic Dermatitis. N Engl J Med. 2014;371(2):130-9.

18. Gevaert $P$, Lang-Loidolt $D$, Lackner $A$, Stammberger $\mathrm{H}$, Staudinger $\mathrm{H}$, Van Zele T, et al. Nasal IL-5 levels determine the response to anti-IL-5 treatment in patients with nasal polyps. J Allergy Clin Immunol. 2006;118(5):1133-41.

19. Pinto JM, Mehta $N$, DiTineo $M$, Wang J, Baroody FM, Naclerio RM. A randomized double-blind, placebo-controlled tria of anti-lgE for chronic rhinosinusitis Rhinology. 2010;48(3):318-24

20. Gevaert P, Van Bruaene N, Cattaert T, Van Steen K, Van Zele T, Acke F, et al. Mepolizumab, a humanized anti-IL-5 $\mathrm{mAb}$, as a treatment option for severe nasal polyposis. J Allergy Clin Immunol. 2011;128(5):989-95-8.

21. Gevaert P, Calus L, Van Zele T, Blomme K, De Ruyck N, Bauters W, et al. Omalizumab is effective in allergic and nonallergic patients with nasal polyps and asthma. J Allergy Clin Immunol. 2013:131(1):110-6.e1.

22. Bachert C, Mannent L, Naclerio RM, Mullol $J$, Ferguson BJ, Gevaert P, et al. Effect of Subcutaneous Dupilumab on Nasal Polyp Burden in Patients With Chronic Sinusitis and Nasal Polyposis: A Randomized Clinical Trial. JAMA. 2016;315(5):469-79.

23. Bachert C, Sousa AR, Lund VJ, Scadding GK, Gevaert P, Nasser S, et al. Reduced need for surgery in severe nasal polyposis with mepolizumab: Randomized trial. J Allergy Clin Immunol. 2017;140(4):1024-1031.e14.

24. Penn R, Mikula S. The role of anti-lgE immunoglobulin therapy in nasal polyposis: a pilot study. Am J Rhinol;21 (4):428-32.

25. Grundmann SA, Hemfort PB, Luger TA, Brehler R. Anti-lgE (omalizumab): a new therapeutic approach for chronic rhinosinusitis. J Allergy Clin Immunol. 2008;121(1):257-8.

26. Guglielmo M, Gulotta C, Mancini F, Sacchi
M, Tarantini F. Recalcitrant nasal polyposis: achievement of total remission following treatment with omalizumab. J Investig Allergol Clin Immunol. 2009;19(2):158-9.

27. Vennera Mdel C, Picado C, Mullol J, Alobid I B-SM. Efficacy of omalizumab in the treatment of nasal polyps. Thorax. 2011;66(9):823-4.

28. Hong CJ, Tsang AC, Quinn JG, Bonaparte JP, Stevens A, Kilty SJ. Anti-lgE monoclonal antibody therapy for the treatment of chronic rhinosinusitis: a systematic review. Syst Rev. 2015:4:166

29. Santos TS, Gonçalves P, Carvalho C. Effectiveness of Omalizumab in the Treatment of Chronic Rhinosinusitis With Nasal Polyps: Systematic Review. 2014:3:473-9.

30. Fernández, C., Busse, W., Reisner, C., and Gupta, N. Clinical data do not suggest a causal relationship between omalizumab therapy and cancer. Proc Am Thorac Soc. 2005: 2: A359

31. Genentech, Inc. Xolair (omalizumab) [product insert]. South San Francisco; 2007

32. Corren J, Casale TB, Lanier B, Buhl R, Holgate S, Jimenez P. Safety and tolerability of omalizumab. Clin Exp Allergy. 2009;39(6):788-97.

33. Long A, Rahmaoui A, Rothman KJ, Guinan E, Eisner M, Bradley MS, et al. Incidence of malignancy in patients with moderateto-severe asthma treated with or without omalizumab. J Allergy Clin Immunol. 2014;134(3):560-567.e4

34. Castro M, Mathur S, Hargreave F, Boulet L-P, Xie F, Young J, et al. Reslizumab for poorly controlled, eosinophilic asthma: a randomized, placebo-controlled study. Am J Respir Crit Care Med. 2011;184(10):1125-32.

35. Ghazi A, Trikha A, Calhoun WJ. Benralizumab--a humanized mAb to IL-5Ra with enhanced antibody-dependent cellmediated cytotoxicity--a novel approach for the treatment of asthma. Expert Opin Biol Ther. 2012;12(1):113-8.

36. Laviolette M, Gossage DL, Gauvreau G, Leigh R, Olivenstein R, Katial R, et al. Effects of benralizumab on airway eosinophils in asthmatic patients with sputum eosinophilia. J Allergy Clin Immunol. 2013;132(5):1086-1096.e5.

37. Walsh GM. An update on biologic-based therapy in asthma. Immunotherapy. 2013;5(11):1255-64.

38. Subcutaneous omalizumab for treatment of chronic rhinosinusitis with nasal polyposis (Xolair CRS). ClinicalTrials.gov Identifier: NCT01066104

39. Effect of Reslizumab in Chronic Rhinosinusitis ClinicalTrials.gov Identifier: NCT02799446

40. A Controlled Clinical Study of Dupilumab in
Patients With Nasal Polyps ClinicalTrials.gov Identifier: NCT02912468

41. Controlled Clinical Study of Dupilumab in Patients With Nasal Polyps ClinicalTrials.gov Identifier: NCT02898454

42. Menzella F, Galeone C, Bertolini F, Castagnetti C, Facciolongo N. Innovative treatments for severe refractory asthma: how to choose the right option for the right patient? J Asthma Allergy. 2017;Volume10:237-47.

43. Vennera M del C, Valero A, Uría E, Forné C, Picado C. Cost-Effectiveness Analysis of Omalizumab for the Treatment of Severe Persistent Asthma in Real Clinical Practice in Spain. Clin Drug Investig. 2016;36(7):567-78.

44. Kuznik A, Bégo-Le-Bagousse G, Eckert L, Gadkari A, Simpson E, Graham CN, et al. Economic Evaluation of Dupilumab for the Treatment of Moderate-to-Severe Atopic Dermatitis in Adults. Dermatol Ther (Heidelb). 2017 Dec;7(4):493-505.

45. Whittington MD, McQueen RB, Ollendorf DA, Tice JA, Chapman RH, Pearson SD, et al. Assessing the value of mepolizumab for severe eosinophilic asthma: a costeffectiveness analysis. Ann Allergy, Asthma Immunol. 2017;118(2):220-5.

46. De Schryver E, Derycke L, Calus L, Holtappels G, Hellings PW, Van Zele T, et al. The effect of systemic treatments on periostin expression reflects their interference with the eosinophilic inflammation in chronic rhinosinusitis with nasal polyps. Rhinology. 2017;55(2):152-160.

Konstantinos Markou, MD, PhD

Assistant professor

2nd Academic Otorhinolaryngology -

Head and Neck Surgery Department

Aristotle University of Thessaloniki

Papageorgiou Hospital

Ring Road, Efkarpia

Thessaloniki

Greece

Tel.: +30-2313-323132

$+30-6932-721545$

Fax: +30 2310991556

E-mail:kmarkou@med.auth.gr 